\title{
Análise da aplicação do mapeamento do fluxo de valor na identificação de desperdícios do processo de desenvolvimento de produtos
}

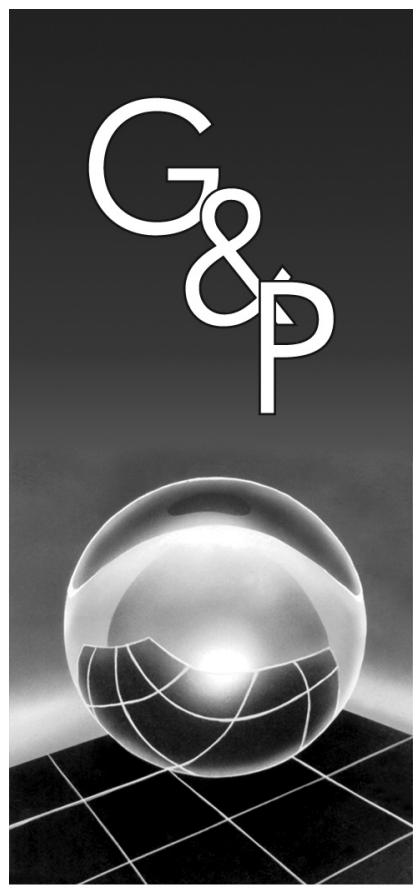

\author{
Eduardo Gomes Salgado \\ Carlos Henrique Pereira Mello \\ Carlos Eduardo Sanches da Silva \\ Eduardo da Silva Oliveira \\ Dagoberto Alves de Almeida
}

Resumo

O processo de desenvolvimento de produtos se torna cada vez mais crítico para a competitividade das empresas devido a crescente internacionalização dos mercados, aumento da diversidade e variedade de produtos e redução do ciclo de vida dos produtos. $O$ presente trabalho tem como objetivo principal avaliar a contribuição da utilização da técnica de mapeamento lean no processo de desenvolvimento de produtos. O método utilizado é o estudo de caso realizado em uma empresa do sul de Minas que possui ciclos de desenvolvimento de produtos curtos, médios e longos. A aplicação do mapeamento de fluxo de valor, ferramenta da filosofia lean, no desenvolvimento de produtos identificou desperdícios dentro do processo de desenvolvimento, nas interfaces entre os agentes envolvidos, a partir da análise do processo de desenvolvimento de holders. Algumas adaptações foram necessárias, mas a pesquisa mostrou que a confecção dos mapas do estado atual e futuro na linguagem padronizada pela fisolofia lean pode ser aplicada no processo de desenvolvimento de produtos.

Palavras-chave: Desenvolvimento de produtos. Pensamento lean. Desenvolvimento lean. Fluxo de valor. Mapeamento do processo.

\section{Introdução}

O mercado passa por transformações que formam um novo contexto dinâmico para as organizações e, em especial, na indústria brasileira. Seus produtos têm de competir em preço e qualidade com similares estrangeiros, vindos tanto de países com elevado nível de desenvolvimento tecnológico quanto de países onde os custos de fabricação estão num patamar bem mais baixo. Isso força a empresa brasileira a assimilar e desenvolver continuamente novas tecnologias e produtos visando a redução de custos, do tempo de desenvolvimento de novos produtos, das não conformidades, da manutenção e, se possível, a ampliação de mercado.

Segundo Wheelright e Clark (1992), num ambiente global, intenso e dinâmico, o desenvolvimento de novos produtos tornou-se um ponto de excelência. Empresas que conquistam mercados mais rápida e eficientemente com produtos que atendem às expectativas dos clientes e as excedem, criam uma significativa alavancagem competitiva.

A abordagem científica da filosofia lean foi inicialmente divulgada nos trabalhos de Womack, Jones e Roos (1992),
Shingo (1981), Womack e Jones (1996) e Hines, Holweg e Rich (2004), sendo posteriormente transposta para o processo de desenvolvimento de produtos. Pesquisas de Sohal e Egglestone (1994), Karlssson e Ahlström (1996), Bauch (2004) e Machado (2006) tiveram como foco a avaliação das potencialidades da aplicação da filosofia lean na área de pesquisa e de desenvolvimento, verificação das dificuldades de implementação do lean development, proposição de desperdícios para o lean development $\mathrm{e}$ uma sistemática para a implementação da filosofia lean no PDP, seguindo a estrutura de projetos, respectivamente. As pesquisas citadas mencionam o uso do mapeamento do fluxo de valor como meio para identificação dos desperdícios do PDP. Porém, elas se limitam a abordá-lo teoricamente, não descrevendo nenhuma aplicação empírica, que é a contribuição da presente pesquisa.

Com base no que foi exposto, deduz-se que a identificação e a mitigação de fatores de desperdício (de tempo, de atividades desnecessárias, de retrabalhos, etc.) no processo de desenvolvimento de produtos podem reduzir o lead time 
deste processo, podendo trazer uma vantagem competitiva para uma organização. O mapeamento do fluxo de valor é uma ferramenta que poderia operacionalizar esta análise, pela identificação das atividades que agregam e que não agregam valor ao processo. A realização desta presente pesquisa busca responder à seguinte questão de pesquisa: a redução dos desperdícios do processo de desenvolvimento de produtos de uma empresa, apoiada pelo mapeamento do fluxo de valor, contribui para a redução do lead time deste processo?

Para responder a esta questão de pesquisa, o objetivo principal deste trabalho é investigar se a aplicação do mapeamento do fluxo de valor, uma ferramenta da filosofia lean, no processo de desenvolvimento de produtos (PDP) de uma empresa permite identificar os desperdícios inerentes ao processo e propor melhorias no sentido de mitigá-los, proporcionando uma redução no lead time do PDP. Como objetivo secundário, mas também importante para estabelecer um arcabouço teórico que contribua para alcançar o objetivo principal, esta pesquisa se propõe a realizar uma pesquisa exploratória a respeito da aplicação da filosofia lean no PDP e identificar os principais desperdícios do processo, bem como as ferramentas que podem ser empregadas na sua mitigação.

Para se atingir esses objetivos foi realizada inicialmente uma revisão de literatura de cunho exploratório para identificar as variáveis pertinentes e levantar os principais desperdícios inerentes ao PDP, assim como as ferramentas que poderiam apoiar sua redução ou eliminação. Posteriormente, foi realizado um estudo de caso em uma pequena empresa multinacional com sede no Brasil para a análise da aplicação do mapeamento do fluxo de valor no PDP. Para a coleta de dados, foram utilizadas as técnicas de entrevista, análise de documentos e observação direta dos processos. Os informantes-chave entrevistados foram: a encarregada e os funcionários do setor de projetos, responsáveis pelo PDP da empresa, a encarregada da área de vendas e o encarregado da área de manufatura auxiliada por computador (CAM).

\section{0 processo de desenvolvimento de produtos}

O PDP pode ser considerado um processo de difícil visualização devido à complexidade de sua gestão, à natureza dinâmica, à sua grande interação com as demais atividades da empresa e a quantidade de informações manipuladas durante um projeto de desenvolvimento. Desse modo, muitas empresas acabam perdendo oportunidades de melhoria e aprendizagem que facilitariam ou possibilitariam o aumento de capacitação e do desempenho do PDP. Uma maneira de evitar essa falha pode ser a gestão desse processo com constantes mudanças, incorporações de lições aprendidas e melhorias contínuas, pela aplicação de modelos sistemáticos e estruturados para análises do PDP (SILVA, 2003).
A literatura pesquisada mostra que cada autor interpreta o processo de desenvolvimento de produtos por uma diferente ótica. Contudo, observa-se que a maioria das fases se repete e muitas variam apenas na terminologia adotada. $\mathrm{O}$ Quadro 1 apresenta uma visão geral de alguns modelos para o processo de desenvolvimento de produtos (BACK, 1983; ROSENTHAL, 1992; VINCENT, 1989; WHEELWRIGHT; CLARK, 1992; COOPER; EDGETT, 1999; PAHL et al., 2005; ROZENFELD et al., 2006).

Em se tratando de empresas de pequeno porte, a pesquisa realizada por O'Dwyer e Ledwith (2009) mostrou que essas empresas devem estar cientes do relacionamento forte entre o desempenho de novo produto e o desempenho organizacional. As empresas que são boas em desenvolver novos produtos são as que têm os melhores resultados. Adicionalmente, a análise mostra que as empresas que são boas em lançamento de produtos têm maior probabilidade de obter sucesso no novo produto; isto é importante para as pequenas empresas. Além disso, as pequenas empresas precisam conhecer seus concorrentes, ou seja, orientação ao concorrente é ligada com o desempenho do novo produto e do desempenho organizacional. Em outras palavras, as pequenas empresas precisam saber quando e porque os clientes compram dos concorrentes e também o que os atrai aos produtos do concorrente.

As pesquisas realizadas por Rozenfeld et al. (2006) apontaram a existência de diversas abordagens para o PDP. Dentre todas, uma das mais citadas na literatura é a abordagem lean no PDP, também conhecida pelo termo lean development, que traz as seguintes contribuições: visão mais orgânica do processo, atingido por meio da máxima simplificação dos trabalhos dos times, com foco nas atividades de prototipagem e testes; possibilidade de retardar ao máximo as decisões de detalhes muito específicos, pois o tempo despendido antecipadamente nesses detalhes deve ser investido em busca de alternativas de soluções e entendimento do problema de projeto. Pensamento enxuto:

O termo lean production (produção enxuta) foi proposto por pesquisadores americanos de forma a traduzir ao mundo ocidental as técnicas utilizadas pela Toyota, introduzidas por Womack, Jones e Roos (1990). Posteriormente, Womack e Jones (1996) ampliaram o termo para pensamento enxuto, enfatizando que o mesmo se aplica a toda a empresa.

De acordo com Womack e Jones (1996), o pensamento enxuto (ou lean thinking) é uma forma de especificar valor, alinhar na melhor sequência as ações que criam valor, realizar essas atividades sem interrupção toda vez que alguém as solicita e realizá-las de forma cada vez mais eficaz. Em suma, o pensamento enxuto é uma forma de fazer cada vez mais com cada vez menos, ou seja, menos esforço humano, equipamento, tempo e espaço e, ao mesmo tempo, aproximar-se cada vez mais de oferecer aos clientes exatamente o que eles desejam. Sendo assim, a base desse 


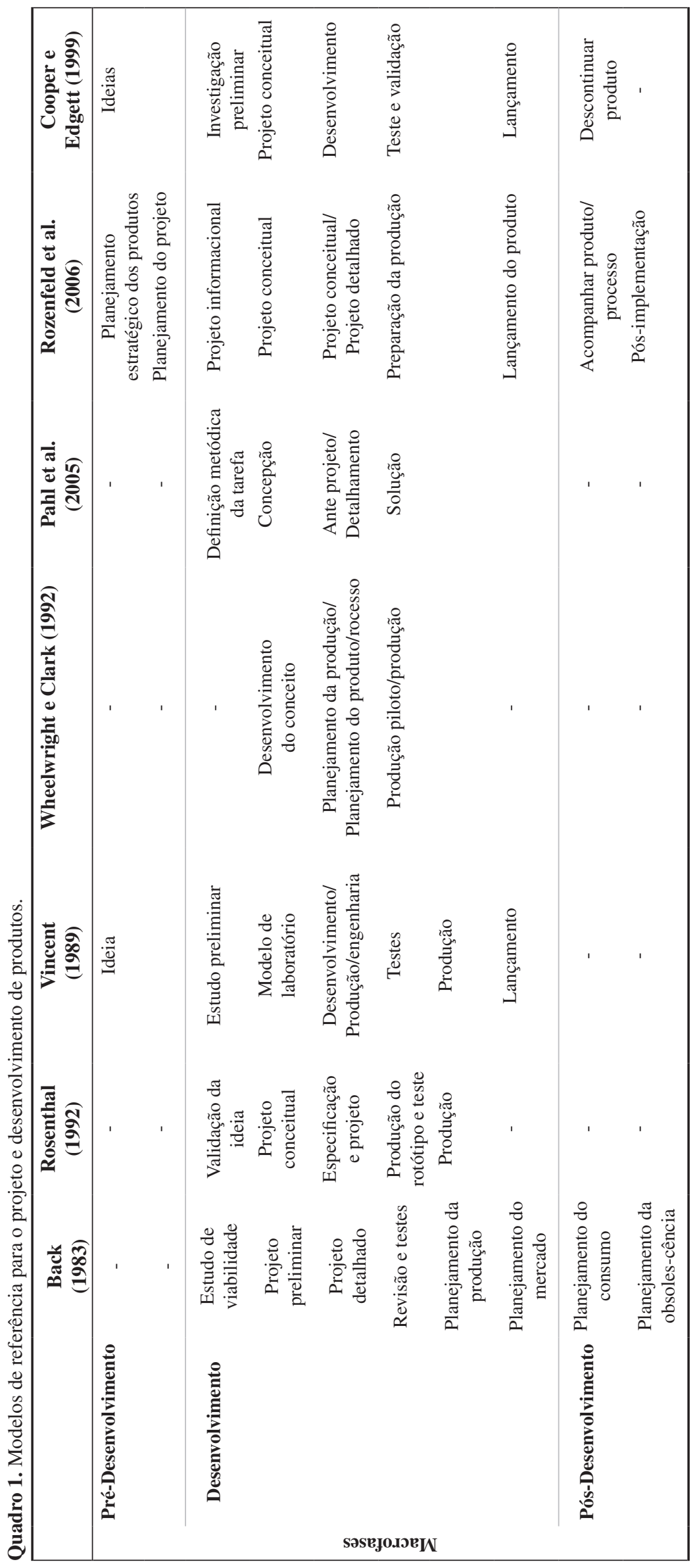

Gest. Prod., São Carlos, v. 16, n. 3, p. 344-356, jul.-set. 2009 
pensamento é localizar e eliminar os desperdícios, sendo eles tudo o que não agrega valor ao cliente.

O crescimento significativo da aplicação do pensamente enxuto nas organizações ocorreu devido à sua nova concepção, validada pelos seus resultados. Concomitantemente, a abordagem enxuta passou a ser o tema de várias pesquisas (HINES; HOLWEG; RICH, 2004; FEARLE; FOWLER, 2006; KEMPTON, 2006).

Segundo Shingo (1981), toda produção, executada tanto na fábrica como no escritório, deve ser entendida como uma rede funcional de processos e operações. Processos transformam matéria-prima em produtos. Operações são ações que executam essas transformações. Esses conceitos fundamentais e sua relação devem ser entendidos para alcançar melhorias efetivas na produção. Para maximizar a eficiência da produção, deve-se analisar profundamente e melhorar o processo antes de se tentar melhorar as operações.

Womack e Jones (1996) estabeleceram cinco princípios para o pensamento enxuto para toda a empresa:

- Valor: capacidade oferecida a um cliente no momento certo a um preço adequado, conforme definido pelo cliente;

- Fluxo de valor: atividades específicas necessárias para projetar, produzir e oferecer um produto específico, da concepção ao lançamento, do pedido à entrega, e da matéria-prima às mãos dos clientes;

- Fluxo: realização progressiva de tarefas ao longo do fluxo de valor para que um produto passe da concepção ao lançamento, do pedido à entrega e da matéria-prima às mãos do cliente sem interrupções, refugos ou retrofluxos;

- Produção puxada: sistema de produção e instruções de entrega das atividades na qual nada é produzido pelo fornecedor sem que o cliente sinalize uma necessidade;

- Perfeição: eliminação total de desperdício para que todas as atividades ao longo de um fluxo de valor criem valor.

- A base do conceito do pensamento enxuto é a eliminação dos desperdícios dentro das empresas. Segundo Ohno (1988), desperdício se refere a todos os elementos de produção que só aumentam os custos sem agregar valor, ou seja, são as atividades que não agregam valor ao produto, do ponto de vista do cliente, mas são realizadas dentro do processo de produção. Shingo (1981) considera que os sete desperdícios para o Sistema Toyota de Produção (STP) são:

- Superprodução: produzir excessivamente ou cedo demais, resultando em um fluxo pobre de peças e informações ou excesso de inventário;

- Espera: longos períodos de ociosidade de pessoas, peças e informação, resultando em um fluxo pobre, bem como em lead times longos;
- Transporte excessivo: movimento excessivo de pessoas, informação ou peças, resultando em dispêndio desnecessário de capital, tempo e energia;

- Processos inadequados: utilização do jogo errado de ferramentas, sistemas ou procedimentos, geralmente quando uma aproximação mais simples pode ser mais efetiva;

- Inventário desnecessário: armazenamento excessivo e falta de informação ou produtos, resultando em custos excessivos e baixo desempenho do serviço prestado ao cliente;

- Movimentação desnecessária: desorganização do ambiente de trabalho, resultando em baixo desempenho dos aspectos ergonômicos e perda frequente de itens;

- Produtos defeituosos: problemas frequentes nas cartas de processo, problemas de qualidade do produto ou baixo desempenho na entrega.

Com a finalidade de eliminar esses sete desperdícios, Godinho Filho e Fernandes (2004) apresentaram as ferramentas aplicáveis a cada um dos princípios mais importantes da manufatura enxuta (vide Quadro 2).

Fundamentado que o pensamento enxuto pode ser aplicado em qualquer processo de uma empresa, ele pode tornar-se uma abordagem do PDP. Além dos sete desperdícios levantados por Shingo (1981) para o pensamento enxuto, Bauch (2004) propôs ainda outros três desperdícios para o PDP:

- Reinvenção: o desperdício está em reinventar processos, soluções, métodos e produtos que já existem ou que somente necessitariam de poucas modificações para torná-los adequados ao problema em questão;

- Falta de disciplina: o desperdício está em objetivos e metas mal definidos; papéis, responsabilidades e direitos não declarados ou não informados; regras mal definidas; definição pobre de dependência entre atividades; insuficiente predisposição para cooperar; incompetência ou treinamento pobre.

- Integração de tecnologia da informação (TI): a grande variedade de componentes de TI (hardware, software, redes, etc.) e o desafio de conseguir mapear todo o processo de desenvolvimento de forma integrada que viabilize não somente o uso das ferramentas atuais mas também as futuras levam a problemas de compatibilidade, capacidade e disponibilidade baixas.

O Quadro 3 mostra uma comparação da definição dos desperdícios para manufatura e sua adaptação para o processo de desenvolvimento de produtos.

Para Bauch (2004), o desenvolvimento de produto é diferente da manufatura, pois pode ser compreendido como algum tipo da fábrica de criação de informação: criar informação, recolher, avaliar e reduzir o risco e a incerteza, ao mesmo tempo com a meta para desenvolver gradualmente 
Quadro 2. Princípios da manufatura enxuta e ferramentas aplicáveis.

\begin{tabular}{|c|c|}
\hline Princípios & Ferramentas \\
\hline $\begin{array}{l}\text { Determinar valor para o cliente, } \\
\text { identificando cadeia de valor e } \\
\text { eliminando desperdícios. }\end{array}$ & $\begin{array}{l}\text { - Mapeamento do fluxo de valor; } \\
\text { - Melhoria na relação cliente-fornecedor/redução do número de fornecedores; } \\
\text { - Recebimento/fornecimento just in time. }\end{array}$ \\
\hline Trabalho em fluxo/simplificar fluxo. & $\begin{array}{l}\text { - Tecnologia de grupo; } \\
\text { - Trabalho em fluxo contínuo (one piece flow)/redução do tamanho de lote; } \\
\text { - Trabalhar de acordo com o takt time/produção sincronizada; } \\
\text { - Manutenção produtiva total (TPM). }\end{array}$ \\
\hline Produção puxada/just in time. & $\begin{array}{l}\text { - Kanban; } \\
\text { - Redução do tempo de set up. }\end{array}$ \\
\hline Busca da perfeição. & - Kaizen; \\
\hline Autonomação/qualidade seis sigma. & $\begin{array}{l}\text { - Ferramentas de controle da qualidade; } \\
\text { - Zero defeito; } \\
\text { - Ferramentas poka yoke. }\end{array}$ \\
\hline Limpeza, ordem e segurança. & - $5 \mathrm{~S}$. \\
\hline $\begin{array}{l}\text { Desenvolvimento e capacitação de } \\
\text { recursos humanos. }\end{array}$ & $\begin{array}{l}\text { - Empowerment; } \\
\text { - Trabalho em equipes; } \\
\text { - Comprometimento dos funcionários e da alta gerência; } \\
\text { - Trabalhador multi-habilitado/rodízio de funções; } \\
\text { - Treinamento de pessoal. }\end{array}$ \\
\hline Gerenciamento visual. & $\begin{array}{l}\text { - Medidas de desempenho/balanced scorecard; } \\
\text { - Gráficos de controle visuais. }\end{array}$ \\
\hline $\begin{array}{l}\text { Adaptação de outras áreas da } \\
\text { empresa ao pensamento enxuto. }\end{array}$ & $\begin{array}{l}\text { - Modificação de estrutura financeira/custos; } \\
\text { - Ferramentas para projeto enxuto (projeto para manufatura e montagem - DFM }\end{array}$ \\
\hline
\end{tabular}

Fonte: Godinho Filho e Fernandes (2004).

um produto novo e sem erros que, então, possa ser realizado na fábrica. No contraste, o alvo da manufatura é reproduzir sem erros exatamente o mesmo produto repetidas vezes e, dependendo do setor industrial, esse valor pode variar entre dúzias e centenas dos milhares.

Analisando-se e relacionando-se os Quadros 2 e 3, pode-se identificar as ferramentas que melhor se adaptam para mitigar os desperdícios do processo de desenvolvimento de produtos, como mostra o Quadro 4.

Analisando-se o Quadro 4, percebe-se que o mapeamento do fluxo de valor (ou mapeamento lean) é um meio para a identificação de todos os desperdícios. Isso pode ser evidenciado nas diversas pesquisas realizadas (SOHAL; EGGLESTONE, 1994; KARLSSSON e AHLSTRÖM, 1996; BAUCH, 2004; MACHADO, 2006) sobre a filosofia lean aplicada ao processo de desenvolvimento de produtos.

\section{Mapeamento lean}

Segundo Leal (2003), o conhecimento do Just in Time, apesar de ter sido originado a partir de processos de manufatura, contribui para o enriquecimento da análise do mapeamento e caracterização de processos de prestação de serviço. Um dos principais focos da filosofia Just in Time é a redução de desperdícios. Neste sentido, a observação do processo do ponto de vista da agregação de valor é fundamental.

Basicamente, o termo valor agregado pode ser entendido a partir da visão do cliente do processo em atividades que agregam valor, atividades desnecessárias que não agregam valor e atividades necessárias que não agregam valor.

As principais técnicas existentes para a representação das atividades de um processo são os fluxogramas, os mapofluxogramas, o blueprint, as técnicas $\mathrm{IDEF}_{0}$ a IDEF $_{9}$ e o mapeamento do fluxo de valor.

O mapeamento do PDP focando a redução de desperdícios é realizado de forma a determinar o nível de agregação de valor das atividades para o cliente. Diversos autores aplicaram o mapeamento do fluxo de valor em outras áreas, como Taylor (2005) Lasa, Laburu e Vila (2008), Seth, Seth e Goel (2008), Coronado M. e Lyons (2007) e Hines, Francis e Found (2006). Nesse sentido, o mapeamento do fluxo de valor ou mapeamento lean parece ser a ferramenta mais adequada para se atingir os objetivos da presente pesquisa. 
Quadro 3. Relação entre os desperdícios no processo de desenvolvimento de produtos e na manufatura.

\begin{tabular}{|c|c|c|c|}
\hline & Desperdícios & Manufatura & Desenvolvimento de Produtos \\
\hline 1 & Espera & $\begin{array}{l}\text { Material e partes de operações procedentes. } \\
\text { Manutenção. } \\
\text { Ferramentas. } \\
\text { Operadores. } \\
\text { Fila para operações adicionais. }\end{array}$ & $\begin{array}{l}\text { Capacidade disponível do homem ou máquina. } \\
\text { Informações esperando por pessoas. } \\
\text { Espera por dados, respostas, requisitos, especificações, } \\
\text { resultados de testes, aprovações, decisões, eventos de } \\
\text { revisão, assinaturas. }\end{array}$ \\
\hline 2 & Transporte & $\begin{array}{l}\text { Movimento excessivo de peças, } \\
\text { matérias, peças e produtos. } \\
\text { Movimentação para armazenamento. } \\
\text { Tirar e colocar o material/produto/peça. }\end{array}$ & $\begin{array}{l}\text { Excessivo tráfego de dados. } \\
\text { Ir e vir das tarefas ou tarefas interrompidas. } \\
\text { Comunicação ineficiente. }\end{array}$ \\
\hline 3 & $\begin{array}{l}\text { Movimentação } \\
\text { desnecessária }\end{array}$ & $\begin{array}{l}\text { Movimentos mínimos dos operadores } \\
\text { (alcançar, dobrar-se, fazer força). }\end{array}$ & $\begin{array}{l}\text { Locais remotos. } \\
\text { Busca de informações. } \\
\text { Falta de acesso direto. }\end{array}$ \\
\hline 4 & $\begin{array}{c}\text { Processos } \\
\text { inadequados }\end{array}$ & $\begin{array}{l}\text { Superdimensionamento do processo, } \\
\text { máquinas e equipamentos. }\end{array}$ & $\begin{array}{l}\text { Precisão e detalhes desnecessários. } \\
\text { Processos e características desnecessários. } \\
\text { Uso inadequado das competências. }\end{array}$ \\
\hline & & $\begin{array}{l}\text { Precisão desnecessária do produto ou do processo, } \\
\text { não compatível com a real necessidade do cliente. }\end{array}$ & $\begin{array}{l}\text { Uso inapropriado de ferramentas e métodos. } \\
\text { Precisão excessiva. } \\
\text { Transações excessivas. }\end{array}$ \\
\hline 5 & Inventário & $\begin{array}{l}\text { Estoque excessivo de matéria - prima, produtos } \\
\text { semiacabados e produtos acabados comparados } \\
\text { com a demanda do cliente. }\end{array}$ & Excessivo armazenamento de dados. \\
\hline & & $\begin{array}{l}\text { Filas. } \\
\text { Estoque entre operações. }\end{array}$ & $\begin{array}{l}\text { Testes desnecessários de equipamentos e protótipos. } \\
\text { Filas no caminho crítico. }\end{array}$ \\
\hline 6 & Superprodução & Produzir a mais do que o solicitado pelo cliente. & $\begin{array}{l}\text { Baixo sincronismo do tempo considerado e a capacidade. } \\
\text { Baixo sincronismo dos conteúdos considerados. }\end{array}$ \\
\hline & & Produzir antes do solicitado pelo cliente. & $\begin{array}{l}\text { Excesso de disseminação de informação. } \\
\text { Redundância das tarefas. }\end{array}$ \\
\hline 7 & Defeitos & $\begin{array}{l}\text { Componentes, materiais, submontagens ou } \\
\text { produtos que não possuem a qualidade requerida. } \\
\text { Defeitos internos na produção. } \\
\text { Defeitos com fornecedores. }\end{array}$ & $\begin{array}{l}\text { Informação com qualidade deficiente. } \\
\text { Dados e informações errôneas. } \\
\text { Testes e verificações pobres. }\end{array}$ \\
\hline 8 & Reinvenção & Não aplicável. & $\begin{array}{l}\text { Reutilização pobre de projetos. } \\
\text { Reutilização pobre de conhecimento. }\end{array}$ \\
\hline 9 & $\begin{array}{l}\text { Falta de } \\
\text { disciplina }\end{array}$ & Não aplicável. & $\begin{array}{l}\text { Objetivos e metas mal elaborados. } \\
\text { Papéis, responsabilidades e direitos mal definidos. } \\
\text { Regras mal elaboradas. } \\
\text { Definição pobre de dependência entre atividades. } \\
\text { Insuficiente predisposição para cooperar. } \\
\text { Incompetência ou treinamento pobre. }\end{array}$ \\
\hline 10 & $\begin{array}{l}\text { Limitações nos } \\
\text { recursos de TI }\end{array}$ & Não aplicável. & $\begin{array}{l}\text { Compatibilidade pobre. } \\
\text { Capabilidade pobre. } \\
\text { Baixa capacidade. }\end{array}$ \\
\hline
\end{tabular}

Fonte: Bauch (2004). 
Quadro 4. Aplicação das ferramentas do pensamento enxuto nos desperdícios do PDP.

\begin{tabular}{|c|c|c|}
\hline \multicolumn{2}{|r|}{ Desperdícios } & Ferramentas \\
\hline 1 & Espera & $\begin{array}{l}\text { - Mapeamento do fluxo de valor; } \\
\text { - Manutenção produtiva total (TPM); } \\
\text { - Melhoria na relação cliente-fornecedor/redução do número de fornecedores; } \\
\text { - } \quad \text { Recebimento/fornecimento just in time. }\end{array}$ \\
\hline 2 & Transporte & $\begin{array}{l}\text { - Mapeamento do fluxo de valor; } \\
\text { - Tecnologia de grupo; } \\
\text { - Trabalho em fluxo contínuo (one piece flow)/redução tamanho de lote; } \\
\text { - Manutenção produtiva total (TPM). }\end{array}$ \\
\hline 3 & Movimentação desnecessária & $\begin{array}{l}\text { - Mapeamento do fluxo de valor; } \\
\text { - } 5 \mathrm{~S} \text {. } \\
\text { - } \quad \text { Trabalho em fluxo contínuo (one piece flow)/redução tamanho de lote. }\end{array}$ \\
\hline 4 & Processos inadequados & $\begin{array}{l}\text { - Mapeamento do fluxo de valor; } \\
\text { - } 5 \mathrm{~S} \text {. }\end{array}$ \\
\hline 5 & Inventário & $\begin{array}{l}\text { - Mapeamento do fluxo de valor; } \\
\text { - Trabalho em fluxo contínuo (one piece flow)/redução tamanho de lote. }\end{array}$ \\
\hline 6 & Superprodução & $\begin{array}{l}\text { - } \quad \text { Mapeamento do fluxo de valor; } \\
\text { - } 5 \mathrm{~S} ; \\
\text { - } \quad \text { Trabalhar de acordo com o takt time/produção sincronizada. }\end{array}$ \\
\hline 7 & Defeitos & $\begin{array}{l}\text { - Mapeamento do fluxo de valor; } \\
\text { - Ferramentas de controle da qualidade; } \\
\text { - Zero defeito; } \\
\text { - Ferramentas poka yoke. }\end{array}$ \\
\hline 8 & Reinvenção & $\begin{array}{l}\text { - Mapeamento do fluxo de valor; } \\
\text { - Medidas de performance/balanced scorecard; } \\
\text { - Tecnologia de grupo; } \\
\text { - Gráficos de controle visuais. }\end{array}$ \\
\hline 9 & Falta de disciplina & $\begin{array}{l}\text { - Mapeamento do fluxo de valor; } \\
\text { - Empowerment; } \\
\text { - Trabalho em equipes; } \\
\text { - Medidas de desempenho/balanced scorecard; } \\
\text { - Comprometimento dos funcionários e da alta gerência; } \\
\text { - Trabalhador multi-habilitado/rodízio de funções; } \\
\text { - Treinamento de pessoal. }\end{array}$ \\
\hline 10 & Limitações nos recursos de TI & $\begin{array}{l}\text { - Mapeamento do fluxo de valor; } \\
\text { - Tecnologia de grupo. }\end{array}$ \\
\hline
\end{tabular}

Conforme Milard (2001), esta ferramenta pode não ser uma garantia de sucesso, no entanto, se utilizada como parte de uma transição global para o lean, seria uma ferramenta útil para o entendimento e melhoria do PDP.

O mapeamento do fluxo de valor para o desenvolvimento de produtos poderia ser realizado de acordo com o seguinte esquema de melhoria (MILARD, 2001): treinar o time no mapeamento do fluxo de valor; selecionar o fluxo de valor para melhoria; definir os elementos do fluxo de valor; analisar e mapear o estado atual; analisar um mapa futuro ou um mapa ideal; implementar novos processos; melhorar continuamente.

Após a caracterização do PDP com ênfase na abordagem lean, fundamentada no pensamento enxuto, descrevem-se os desperdícios adaptados para o desenvolvimento de produtos, destacando-se como meio de identificação o mapeamento lean. Por meio do método do estudo de caso, busca-se responder à questão de pesquisa. 


\section{Estudo de caso}

A unidade de investigação selecionada para o estudo de caso único é uma pequena empresa que atua no mercado de autopeças produzindo Ring Out Boards (ROB). Esses equipamentos são responsáveis pela aprovação elétrica e de componentes de chicotes elétricos. A EMDEP Brasil Ltda. possui ainda unidades fabris na Espanha, México e Marrocos e está localizada na cidade de Itajubá, Minas Gerais, Brasil. A justificativa para a escolha da empresa se deveu à mesma possuir no escopo da certificação ISO 9001:2000, o processo de desenvolvimento de produtos, favorecendo a existência de um modelo sistemático para o PDP; além de ser um caso representativo porque desenvolve produtos com ciclos de desenvolvimento curto, médio e longo, favorecendo os estudos de caso polares. O PDP na EMDEP é constituído pelos processos de vendas, projeto e manufatura apoiada por computador (CAM).

Comparando-se o PDP da empresa objeto de estudo com um modelo de referência, tal como o proposto por Rozenfeld et al. (2006), pode-se verificar que, devido ao tamanho da empresa, várias etapas do modelo de referência são realizadas por um setor ou até mesmo por uma mesma pessoa. O Quadro 5 apresenta um comparativo entre o modelo de referência para PDP proposto por Rozenfeld et al. (2006) e o PDP da empresa objeto de estudo. O PDP da empresa cumpre algumas atividades características de cada fase, pois as atividades não são cumpridas integralmente.

O desenvolvimento do produto é realizado sob encomenda. Nesse tipo de desenvolvimento acontecem mudanças mais profundas nas fases iniciais do processo. Nesse caso, não se desenvolve produto para o mercado, mas sim para atender clientes específicos.

$\mathrm{O}$ artigo se limita a avaliar o mapeamento lean no desenvolvimento de produtos. Dessa forma, os setores comercial e produção não são objetos desse estudo. Assim, os processos internos da empresa que se enquadram nas etapas do modelo estudado são os setores de Desenho e CAM.

A aprovação elétrica é o teste de todos os circuitos pertencentes ao produto, a fim de certificar-se da sua integridade física e da correspondência ao pedido do cliente no que se refere ao posicionamento correto dos circuitos. Já a aprovação de componentes consiste em testar qualquer componente auxiliar que esteja agregado ao produto do cliente tais como buchas, grommets, clips, capas, tampas, presilhas, sacolas, calhas, entre outros.

Cada produto solicitado pelo cliente necessita ser desenvolvido, ou seja, o cliente fornece uma amostra por meio da qual se inicia o PDP e, assim, a EMDEP trabalha no regime produtivo sob encomenda. Esse fato pode caracterizar a empresa como um caso extremo, como citado por Yin (2005), auxiliando a justificativa pela seleção desta empresa para o presente estudo.

Seguindo o esquema de melhoria proposto por Milard (2001), inicialmente foi realizado um treinamento para conscientizar os funcionários das áreas de vendas, desenvolvimento (desenho) e CAM a respeito da ferramenta de mapeamento de fluxo de valor. Esse treinamento não foi exaustivo porque a aplicação da ferramenta no PDP da empresa seria monitorada por integrantes da equipe de pesquisadores. Em segundo lugar, buscando-se atingir o objetivo principal da presente pesquisa, foi selecionado o processo de desenvolvimento de produtos como fluxo de valor a ser melhorado.

Em seguida foram definidos os elementos do fluxo de valor e analisado e mapeado o estado atual do PDP da empresa estudada.

O mapa do estado atual, apresentado na Figura 1, foi desenhado junto aos projetistas durante visita in loco, utilizando-se do software Igrafx FlowCharter 2006. Durante a confecção do mapa atual foi possível identificar os seguintes desperdícios no PDP da empresa estudada: espera por liberação do projeto, problemas de incompatibilidade, reutilização pobre do conhecimento, reutilização pobre de projetos, deslocamento físico dos funcionários, reutilização pobre do conhecimento, retrabalho, tarefas interrompidas e filas no caminho crítico.

O mapeamento do fluxo de valor do macroprocesso de desenvolvimento de produto foi realizado a partir de informações coletadas em entrevistas com os encarregados e funcionários das áreas de vendas, desenvolvimento e CAM da empresa, coleta de dados da empresa e da observação

Quadro 5. Comparativo entre as fases do modelo de referência e o PDP da empresa.

\begin{tabular}{|lcccc|}
\hline \multicolumn{1}{|c}{ PDP da empresa } & Comercial & Desenho (projeto) & CAM & Produção \\
\hline Fases do modelo de referência & & - & - & - \\
Planejamento estratégico dos produtos & $\times$ & - & - & - \\
Planejamento do projeto & $\times$ & $\times$ & $\times$ & - \\
Projeto informacional & - & $\times$ & - & - \\
Projeto conceitual & - & $\times$ & - & $\times$ \\
Projeto detalhado & - & - & - & $\times$ \\
Preparação da produção & - & - & - & $\times$ \\
Lançamento do produto & - & - & \\
Acompanhar produto/processo & - & - & & $\times$ \\
Descontinuar produto & - & & & \\
\hline
\end{tabular}


direta pelo pesquisador do fluxo de atividades. Por meio desses mecanismos de coleta de dados foram levantados os tempos para o mapeamento do fluxo de valor. A coleta de dados consumiu um mês. O Quadro 6 apresenta a definição de cada desperdício identificado na empresa estudada, assim como sua relação com os desperdícios citados na literatura (dados pelo Quadro 3). O Quadro 7 apresenta as principais características dos entrevistados.

Não foi possível identificar durante a pesquisa os desperdícios citados na literatura de processos inadequados, superprodução e falta de disciplina. Eles não foram observados durante a pesquisa empírica.

Uma vez realizado este mapa, propôs-se, com base nos princípios enxutos, a eliminação dos desperdícios identificados no estado atual e a elaboração de um mapa futuro com a implantação das propostas de melhoria, como pode ser visto na Figura 2. Os tempos levantados e o work in progress proposto no mapa do estado futuro foram estimados levando-se em consideração a experiência dos funcionários, observação dos pesquisadores e coleta de dados históricos.

A aplicação do mapeamento de fluxo de valor, ferramenta da filosofia Lean, no desenvolvimento de produtos, identificou desperdícios dentro do processo de desenvolvimento de produtos da empresa estudada, nas interfaces entre os agentes envolvidos a partir da análise do estudo de caso do desenvolvimento de ROBs, tais como, reutilização pobre de projeto, movimentação de pessoas de forma desnecessária, verificação de problemas de compatibilidade, espera por liberação do projeto, reutilização pobre de conhecimento e distância entre os setores.

A Figura 2 mostra o mapa do estado futuro, que é a representação da situação ideal do PDP da empresa estudada. Em razão disso, os balões (explosões) dos desperdícios foram eliminados em relação à representação feita na Figura 1. Assim, como a empresa deseja eliminar os desperdícios foram eliminados os balões e o tempo do estado futuro do processo é o tempo do estado atual sem os desperdícios. Assim, o mapa do estado futuro apresenta o quanto a empresa pode melhorar com as eliminações dos desperdícios.

O levantamento dos dados no estado atual e no estado futuro sugere melhoria no PDP com a implementação da filosofia lean, pois o lead time, a taxa de agregação de valor e a eficiência apresentaram melhorias, como mostra a Tabela 1 .

Com a utilização do Mapeamento de Valor foi possível identificar e propor mudanças para melhorar o processo de desenvolvimento de produtos. Analisando-se as Figuras 1 e 2, percebe-se que a empresa teria um ganho de eficiência e diminuiria o lead time do desenvolvimento, o que lhe traria uma vantagem competitiva.



Figura 1. Estado atual do PDP da empresa estudada. 
Quadro 6. Caracterização dos desperdícios identificados no estudo de caso.

\begin{tabular}{|c|c|c|c|c|c|}
\hline \multicolumn{2}{|c|}{ Desperdício } & \multirow{2}{*}{$\begin{array}{l}\text { Comentários das causas } \\
\text { relevantes dos desperdícios }\end{array}$} & \multicolumn{3}{|c|}{ Coleta de dados } \\
\hline Teórico & Empírico & & Entrevista & Observação & $\begin{array}{c}\text { Análise } \\
\text { documental }\end{array}$ \\
\hline Espera & $\begin{array}{l}\text { Espera por } \\
\text { liberação do } \\
\text { projeto }\end{array}$ & $\begin{array}{r}\text { Ordens de serviço incompletas (especificações de } \\
\text { projeto), falta de amostra dos conectores e conectores } \\
\text { danificados. }\end{array}$ & $x$ & $x$ & $x$ \\
\hline $\begin{array}{l}\text { Limitações nos } \\
\text { recursos de TI }\end{array}$ & $\begin{array}{l}\text { Problemas de } \\
\text { incompatibilidade }\end{array}$ & $\begin{array}{l}\text { Recepção de arquivos de clientes com extensão } \\
\text { incompatível com os softwares utilizados na empresa. }\end{array}$ & $x$ & - & - \\
\hline $\begin{array}{l}\text { Movimentação } \\
\text { desnecessária }\end{array}$ & $\begin{array}{l}\text { Deslocamento } \\
\text { físico dos } \\
\text { funcionários }\end{array}$ & $\begin{array}{l}\text { Parte dos recursos (cópias, arquivos físicos, CAM, etc.) } \\
\text { utilizados no PDP necessita de que o funcionário se } \\
\text { desloque significativamente de sua estação de trabalho. }\end{array}$ & $x$ & $x$ & - \\
\hline \multirow[t]{2}{*}{ Reinvenção } & $\begin{array}{l}\text { Reutilização pobre } \\
\text { do conhecimento }\end{array}$ & $\begin{array}{l}\text { A formação de um projetista da empresa é feita } \\
\text { principalmente por treinamento no posto de trabalho. } \\
\text { Porém, o reduzido número de projetistas e o elevado } \\
\text { número de projetos não permite a captação e } \\
\text { socialização do conhecimento gerado. Além disso, a } \\
\text { troca de conhecimento entre as unidades existentes em } \\
\text { outros países ocorre informalmente quando o projetista } \\
\text { é parcialmente alocado em outra unidade para atender } \\
\text { ao aumento na demanda de projetos. O mecanismo } \\
\text { corporativo de gestão do conhecimento é restrito aos } \\
\text { registros dos projetos. }\end{array}$ & $x$ & $x$ & $x$ \\
\hline & $\begin{array}{l}\text { Reutilização } \\
\text { pobre de projetos }\end{array}$ & $\begin{array}{r}\text { Todos os projetos são cadastrados, porém a sua } \\
\text { indexação entre as plantas de outros países não } \\
\text { existia. Com a implantação de um banco de dados } \\
\text { unificado a duplicação de projetos teve uma acentuada } \\
\text { redução. Porém, ainda existem projetos que não foram } \\
\text { cadastrados. }\end{array}$ & $x$ & $x$ & $x$ \\
\hline Defeitos & $\begin{array}{l}\text { Retrabalho - } \\
\text { informação } \\
\text { errônea do projeto }\end{array}$ & $\begin{array}{l}\text { Retrabalhos encontrados foram devido a informações } \\
\text { erradas como silhueta justa, tampa não conforme, não } \\
\text { garantia de alinhamento dos terminais e conector com } \\
\text { travamento incorreto. }\end{array}$ & $x$ & $x$ & $x$ \\
\hline Transporte & $\begin{array}{l}\text { Ir e vir das } \\
\text { tarefas/ tarefas } \\
\text { interrompidas }\end{array}$ & $\begin{array}{l}\text { Ocorre quando o setor da produção tem dúvidas com } \\
\text { relação ao produto do projeto e se desloca ao setor do } \\
\text { PDP para sanar a dúvida, interrompendo a atividade do } \\
\text { projetista. Os projetistas, ao final do desenvolvimento, } \\
\text { transportam as informações até o setor do CAM. } \\
\text { Grande parte da comunicação é direta, apesar de } \\
\text { existirem outros meios (registros, documentos, } \\
\text { telefone, e-mail, etc.). Por ser a empresa de pequeno } \\
\text { porte, prefere-se a comunicação direta. }\end{array}$ & $x$ & $x$ & - \\
\hline Inventário & $\begin{array}{l}\text { Filas no } \\
\text { caminho crítico }\end{array}$ & $\begin{array}{r}\text { Foram identificadas filas no setor do CAM para } \\
\text { desenvolvimento dos projetos. }\end{array}$ & $x$ & $x$ & - \\
\hline
\end{tabular}

Quadro 7. Características dos entrevistados.

\begin{tabular}{|c|c|c|c|c|c|c|}
\hline \multirow[t]{2}{*}{ Características } & \multicolumn{6}{|c|}{ Entrevistados } \\
\hline & 1 & 2 & 3 & 4 & 5 & 6 \\
\hline Tempo de EMDEP (anos) & 5 & 7 & 5 & 1 & 1 & 1,0 \\
\hline Tempo na função (anos) & 4,75 & 7 & 2 & 1 & 1 & 0,5 \\
\hline Formação acadêmica & $\begin{array}{c}\text { Técnico informática } \\
\text { industrial e cursando } \\
\text { administração }\end{array}$ & $\begin{array}{c}\text { Técnico } \\
\text { mecatrônico }\end{array}$ & $\begin{array}{c}\text { Técnico } \\
\text { mecatrônico }\end{array}$ & $\begin{array}{l}2^{\circ} \text { grau } \\
\text { completo }\end{array}$ & $\begin{array}{l}\text { Técnico } \\
\text { mecânico }\end{array}$ & $\begin{array}{l}\text { Técnico } \\
\text { mecânico }\end{array}$ \\
\hline Função & Assistente comercial & Projetista & Projetista & Projetista & Projetista & Programador \\
\hline Área de trabalho & Vendas & Desenho & Desenho & Desenho & Desenho & CAM \\
\hline
\end{tabular}






Figura 2. Estado futuro do PDP da empresa estudada.

Tabela 1. Comparação entre o estado atual e o estado futuro.

\begin{tabular}{lcc}
\hline Indicador & Estado atual & Estado futuro \\
\hline Lead time & 14,6 horas & 6,6 horas \\
Valor agregado & 4,1 horas & 3,1 horas \\
Eficiência & $28,1 \%$ & $47 \%$ \\
\hline
\end{tabular}

\section{Conclusões}

Este trabalho procurou mostrar que a implementação dos conceitos do pensamento enxuto e das ferramentas que nele se aplicam pode ser realizada no processo de desenvolvimento de produtos. A pesquisa permitiu verificar que a ferramenta de mapeamento do fluxo de valor é útil para ser aplicada ao PDP e auxiliar na identificação dos desperdícios, pois, assim como na manufatura, o PDP também possui um fluxo de agregação de valor.

O pensamento enxuto não é apenas um modelo de produção diferenciado que altera os modos usuais de manufatura em uma linha de produção. Sua implementação representa uma mudança geral na empresa, principalmente na cultura das pessoas, podendo ser aplicado em toda empresa, bem como no processo de desenvolvimento de produtos.

A aplicação do mapeamento de fluxo de valor, ferramenta da filosofia lean, no desenvolvimento de produtos, identificou desperdícios dentro do processo de desenvolvimento de produtos da empresa estudada, nas interfaces entre os agentes envolvidos a partir da análise do estudo de caso do desenvolvimento de ROBs.

A eliminação ou mitigação dos desperdícios do PDP de uma empresa auxiliada pelo mapeamento do fluxo de valor pode contribuir para a redução do lead time deste processo. $\mathrm{O}$ objetivo principal da pesquisa foi atingido, pois a aplicação do mapeamento do fluxo de valor no PDP permitiu identificar os desperdícios inerentes ao processo e a proposição de melhorias no sentido de mitigá-los, proporcionando uma redução no lead time do PDP. O lead-time e o valor agregado foram reduzidos na ordem de $54,8 \%$ e $24,4 \%$, respectivamente, e a eficiência aumentou em $67,2 \%$.

Os objetivos secundários desta pesquisa também foram alcançados, pois foi realizada uma pesquisa exploratória a respeito da aplicação da filosofia lean no PDP e identificados os principais desperdícios do processo, bem como as ferramentas que podem ser empregadas na sua mitigação.

Como recomendações para continuidade da pesquisa, sugerem-se realizar um estudo para a priorização das ferramentas do pensamento enxuto no processo de desenvolvimento de novos produtos; realizar uma comparação entre os desperdícios do pensamento enxuto em cada uma das fases do PDP; verificar a aplicabilidade das ferramentas acima citadas em cada uma das fases do PDP, realizar o mapeamento do fluxo de valor e a identificação dos desperdícios lean para os PDPs com as características de projetos radicais, fornecedor de commodities e outro tipo de tecnologia. 


\title{
Analysis of the value flow mapping application to waste identification on the product development process
}

\begin{abstract}
The product development process issue has gradually become more critical to the companies' competitiveness. The reasons are mainly due to the increase in product variety and also the reduction of the life cycle. This work aims to evaluate the Value Stream Mapping contribution to the product development process. The research was conducted in a bakery equipment manufacturing company by means of a case study. For instance, the application of the Lean Value Stream Mapping technique identified many wastes in the holders' product development. The product development process particularities demanded some adaptations to the lean mapping technique. However, the Lean Thinking approach supported by the Value Stream Mapping technique, either the current or the future state, proved fully feasible to be applied in the product development process.
\end{abstract}

Keywords: Product development process. Lean thinking. Lean development. Value flow mapping. Process mapping.

\section{Referências bibliográficas}

BACK, N. Metodologia de projeto de produtos industriais. Rio de Janeiro, RJ: Editora Guanabara Dois, 1983.

BAUCH, C. Lean Product Development: Making waste transparent. Munich, 2004. 140 p. Tese (Doutorado) - Technical University of Munich.

COOPER, R. G.; EDGETT, S. J. Product Development for de Service Sector - Lessons from market leaders. New York, N.Y.: Basic Books, 1999.

CORONADO, M. A. E.; LYONS, A. C. Evaluating operaions flexibility in industrial supply chains to support build-to-order initiatives. Business Process Management Journal, v. 13, n. 4, p. 572-587, 2007.

FEARLE, A.; FOWLER, N. Efficiency versus effectiveness in construction supply chains: the dangers of "lean" thinking in isolation. Supply Chain Management: An International Journal, v. 11, n. 4, p. 283-287, 2006.

GODINHO FILHO, M.; FERNANDES, F. C. F. Manufatura enxuta: uma revisão que classifica e analisa os trabalhos apontando perspectivas de pesquisas futuras. Gestão e Produção, v. 11, n. 1, p.1-19, Jan./Apr. 2004.

HINES, P.; FRANCIS, M.; FOUND, P. Towards lean product lifecycle management. A framework for new product development. Journal of Manufacturing Technology Management, v. 17, n. 7, p. 866-887, 2006.

HINES, P.; HOLWEG, M.; RICH, N. Learnig to envolve. A review of contemporany lean thinking. International Journal of Operations \& Production Management, v. 24, n. 10, p. 994-1011, 2004.

KEMPTON, J. Can lean thinking apply to the repair and refurbishment of properties in the registered social landlord sector? Structural Survey, v. 24, n. 3, p. 201-211, 2006.

LASA, I. S.; LABURU, C. O.; VILA, R. C. An evaluation of the value stream mapping tool. Business Process Management Journal, v. 14, n. 1 , p. $39-52,2008$.

LEAL, F. Um diagnóstico do processo de atendimento a clientes em uma agência bancária através de mapeamento do processo e simulação computacional. Itajubá, MG, 2003. Dissertação (Mestrado do Programa de Pós-Graduação em Engenharia de Produção) - Universidade Federal de Itajubá.
MACHADO, M. C. Princípios enxutos no processo de desenvolvimento de produtos: proposta de uma metodologia para implementação. São Paulo, 2006. Tese (Doutorado) - Escola Politécnica da Universidade de São Paulo, Departamento de Engenharia de Produção, Universidade de São Paulo.

MILARD, R. L. Value stream analysis and mapping for product development. Massachusetts, 2001. Dissertação (Mestrado) Massachusetts Institute of Technology.

O'DWYER, M.; LEDWITH, A. Determinants of new product performance in small firms. International Journal of Entrepreneurial Behaviour \& Research, v. 15, n. 2, p. 124-136, 2009.

OHNO, T. Toyota Production System: Beyond Large-Scale Production. Portland, OR: Productivity Press, 1988.

PAHL, G. et al. Engineering Design: A Systematic Approach. 3 ed. [S.1.]: Springer, 2007.

ROSENTHAL, S. R. Effective Product Design and Development How to cut lead time and increase customer satisfaction. New York, N.Y.: Irwin Professional Publishing, 1992.

ROZENFELD, H. et al. Gestão de desenvolvimento de Produtos - Uma referência para a melhoria do processo. São Paulo: Editora Saraiva, 2006.

SETH, D.; SETH, N.; GOEL, D. Application of value stream mapping (VSM) for minimization of wastes in the processing side of supply chain of cottonseed oil industry in Indian context. Journal of Manufacturing Technology Management, v. 19, n. 4, p. 529-550, 2008.

SHINGO, S. A Study of the Toyota Production System from an Industrial Engineering Viewpoint. [S.1.]: Productivity Press, 1981.

SILVA, M. M. Aprendizagem organizacional no processo de desenvolvimento de produtos: investigação do conhecimento declarativo no contexto da sistemática de stage-gates. São Carlos, 2003. Dissertação (Mestrado) - Universidade Federal de São Carlos.

SOHAL, A. S.; EGGLESTONE, A. Lean production: experience among australian organizations. International Journal of Operations \& Production Management, v. 14, n. 11, p. 35-51, 1994.

TAYLOR, D. H. Value chain analysis: an approach to supply chain improvement in agri-food chains. International Journal of 
Phusical Distribuition \& Logistics Management, v. 35, n. 10, p. 744-761, 2005.

VINCENT, G. Managing new product development. New York, N.Y.: Van Nostrand Reinold, 1989.

WHEELWRIGHT, S. C.; CLARK, K. B. Revolutionizing product development - Quantum Leaps in Speed, Efficiency, and Quality. New York, N.Y.: Free Press, 1992.
WOMACK, J. P.; JONES, D. T.; ROOS, D. The machine that changed the world. New York: Rawson Associates, 1990.

WOMACK, J. P.; JONES, D. T. Lean thinking: Banish waste and create wealth in your corporation. New York: Simon \& Schuster, 1996.

YIN, R. Estudo de caso. Planejamento e métodos. 3 ed. Porto Alegre: Bookman, 2005.

\section{Sobre os autores}

\section{Eduardo Gomes Salgado}

Universidade Federal de Itajubá - UNIFEI

Av. BPS, 1303, Pinheirinho, CEP 37.500-903, Itajubá - MG, Brasil e-mail: egsalgado@yahoo.com.br

\section{Carlos Henrique Pereira Mello}

Universidade Federal de Itajubá - UNIFEI

Av. BPS, 1303, Pinheirinho, CEP 37.500-903, Itajubá - MG, Brasil e-mail: carlos.mello@unifei.edu.br

\section{Carlos Eduardo Sanches da Silva}

Universidade Federal de Itajubá - UNIFEI Av. BPS, 1303, Pinheirinho, CEP 37.500-903, Itajubá - MG, Brasil e-mail: sanches@unifei.edu.br

\section{Eduardo da Silva Oliveira}

Universidade Federal de Itajubá - UNIFEI

Av. BPS, 1303, Pinheirinho, CEP 37.500-903, Itajubá - MG, Brasil e-mail: edu_unifei@yahoo.com.br

\section{Dagoberto Alves de Almeida}

Universidade Federal de Itajubá - UNIFEI

Av. BPS, 1303, Pinheirinho, CEP 37.500-903, Itajubá - MG, Brasil

e-mail: dagoberto@unifei.edu.br

Agradecimentos: A EMDEP pela confiança e oportunidade, a CAPES (Programa Pró-Engenharias - processo PE024/2008), a FAPEMIG (011/07 - TEC APQ 6412-6.01/07) e ao CNPq pela bolsa de mestrado. 